\title{
A NEW ARGENTINE SPECIES OF COCCYGOMIMUS (HYMENOPTERA, ICHNEUMONIDAE)*
}

\author{
By Charles C. Porter \\ Department of Biological Sciences \\ Fordham University \\ Bronx, New York 10458
}

In contrast to other subdivisions of its genus, which include many well known and abundant species, the strictly Neotropical Albomarginatus Group of Coccygomimus comprises insects for the most part elusive, which are found only occasionally even in those areas subject to regular collecting both by hand and by Malaise traps. For this reason, although the author recently published a monograph of the South American Coccygomimus (Porter, 1970), it was expected that new species of the Albomarginatus Group would appear as fieldwork became possible in previously unexplored regions. Indeed, shortly thereafter both sexes of an undescribed species were recovered from a Malaise trap situated in virgin subtropical wet forest near Aguas Blancas in northern Salta Province, practically on the Bolivian border. The present contribution describes this new species, demonstrating that it is related most closely to $C$. ramirezi from the yungas near $\mathrm{La} \mathrm{Paz}$, Bolivia.

Coccygomimus jakulicai new species

$$
\text { (figs. I, 2,4) }
$$

Coccygomimus ramirezi Porter, 1970, Studia Ent. 13: 110, male, desc., fig., Argentina: Posta de Lozano in Jujuy (Tucumán). Male, doubtfully assigned to ramirezi, not conspecific with female holotype.

Holotype: female, ARgentina (Salta: Campamento Jakúlica, $40 \mathrm{~km}$. O. Aguas Blancas, July-August 1970, C. Porter, in Malaise trap) (Tucumán). Paratypes: 2 males, ARgentina (Jujuy: Posta de Lozano, ca. San Salvador de Jujuy, I600 m., March 31, I969, C. Porter; Salta: Campamento Jakúlica, $40 \mathrm{~km}$. O. Aguas Blancas, July-August 1970, C. Porter, in Malaise trap). (Porter, Tucumán).

Female: Color: antenna black; head shining black; mesosoma shining black with yellowish white markings as follows: broad band on much of front margin of pronotum laterally; basally broad but apically much narrowed band on most of lateral part of dorsal margin of pronotum; pair of large, triangular marks on front margin of

*Manuscript received by the editor August 10, 1972 
mesoscutum in position of notauli; all but about centro-exterior $\mathrm{I} / 3$ of the otherwise brownish tegula; all but narrow basal margin and about apical I/4-I/3 of scutellum; very large, irregularly ovoid, vertical blotch on mesopleuron along prepectal carina; most of upper $4 / 5$ of hind-margin of mesopleuron broadly; and a pair of very large blotches, one centered on each hind-corner of propodeum; gaster shining black with complete white apical bands on tergites I-7, an incomplete white apical band on 8 , some pale reddish staining on lateral margins of $4-6$, and extensive pale reddish staining on 7 and 8 ; wings practically hyaline; fore-leg with coxa black with a very large ventro-lateral white blotch that is extensively margined with pale reddish; trochanter black with dull red on apex; trochantellus dull red; femur red with a broad whitish antero-dorsal stripe that extends from apex about $2 / 3$ of the way to the base; tibia pale reddish with considerable dusky staining sub-basally on outer side, a whitish stripe throughout below, and an irregular whitish stripe above which is considerably broadened sub-basally on inner side; and tarsus dull reddish brown with the apical segment dusky; mid-leg with coxa pale red, a little dusky on apex, and with a large, irregular, lateral and latero-ventral white area; trochanter and trochantellus red; femur red with a little dusky staining on apex; tibia with an irregular premedian white annulus basad of which it is blackish and distad of which it is mostly dull pale red; and tarsus dull reddish with the apical segment more nearly black; hind-leg with coxa red except for a little dusky staining on apex; trochanter and trochantellus red with irregular black staining on trochanter; femur red with black staining on about apical I/ıO; tibia black with a little dull red staining and a short premedian white annulus; and tarsus black with a little dull red staining.

Length of fore-wing: $7.1 \mathrm{~mm}$. Face: shining with some fine micro-reticulation and abundant, rather large, mostly subadjacent to adjacent punctures that become densest and in part confluent above. Clypeus: apex deeply emarginate. Temple: 0.73 as long as eye in lateral view. Malar space: $0.9 \mathrm{I}$ as long as basal width of mandible.

Mesoscutum: a little silky-shining with faint micro-reticulation that is most pronounced basad and with abundant, medium sized, subadjacent to adjacent punctures which toward base are densest and partly reticulo-confluent. Scutellum: high and convex, lateral carinae not extending beyond base. Mesopleuron: surface shining, almost throughout with abundant, medium sized to rather large, subadjacent to adjacent or confluent punctures and with extensive, but not uniform, moderately fine intercalated wrinkling. Metapleuron: 

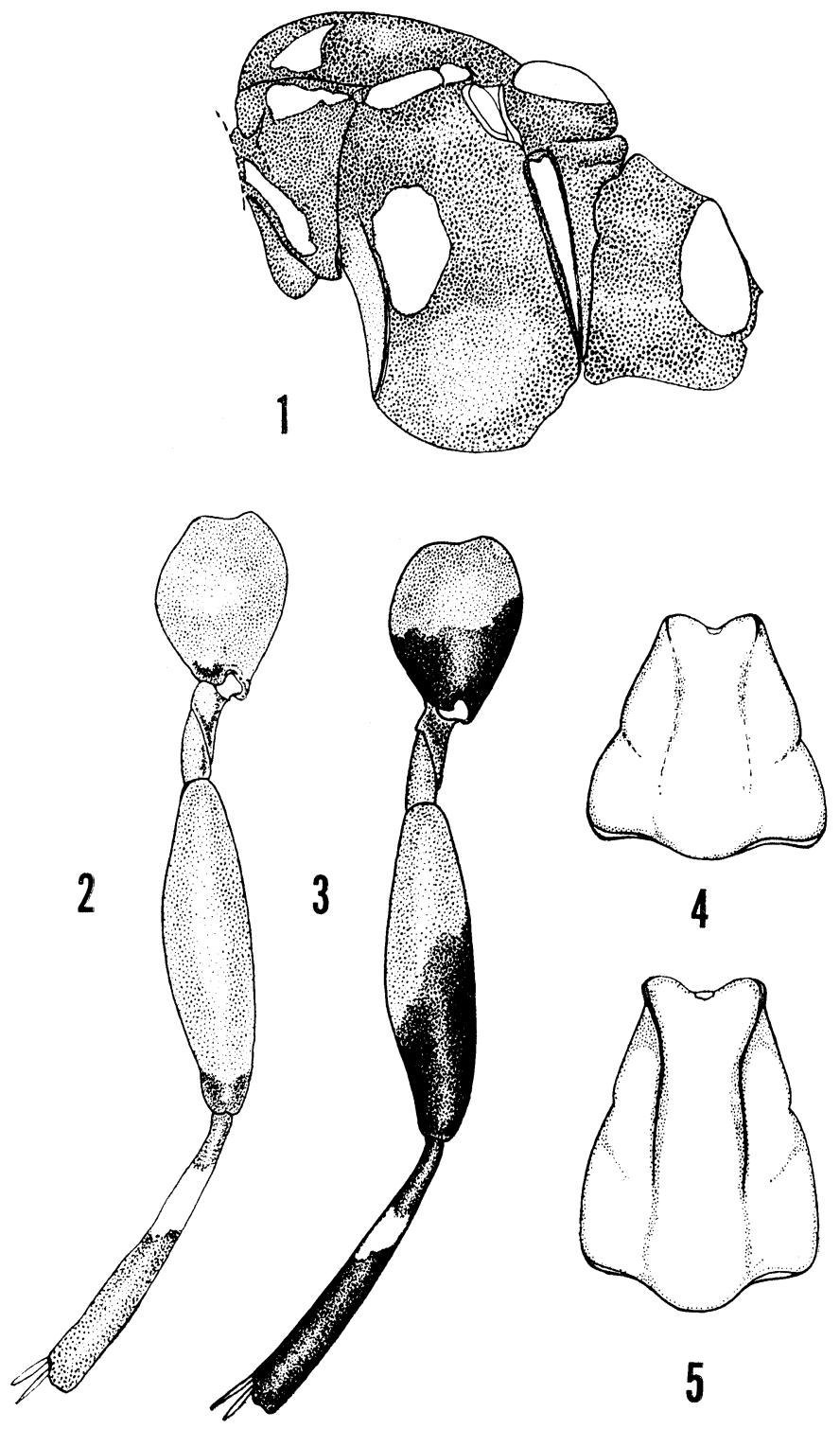
dully shining, on upper $\mathrm{I} / 2$ with rather coarse puncto-reticulation in which the punctures are more or less discrete but on lower $\mathrm{I} / 2$ becoming more regularly obliquely wrinkled with less discrete punctures. Wing venation: nervulus a little postfurcal. Fore-tibia: scarcely inflated.

Propodeum: moderately elongate; median longitudinal carinae weakly suggested because the central area of the basal face is slightly concave throughout; lateral longitudinal carinae scarcely indicated; pleural carina traceable basad, weak and irregular apicad; cristal angles swollen, in form broadly low-pyramidal; basal face shining with moderately fine but strong, nearly regular transverse wrinkling; apical face mostly smooth and shining.

Ist gastric segment: postpetiole 0.65 as long as wide at apex; sternite in profile with a rather low but sharply broad-pyramidal elevation sub-basally; tergite in profile with a rather high, rounded hump; dorsal carinae faintly suggested on hump and for a short distance rearward; surface of postpetiole a little dully to, apicad, more brightly shining and, except on the nearly smooth apical I/4, with fine, irregular to transverse wrinkling and with some intercalated micro-reticulation as well as a number of rather large, faint, mostly well separated punctures. Succeeding tergites: 2 shining with well developed fine micro-reticulation and some widely scattered, shallow, inconspicuous, medium-sized to moderately large punctures; the following tergites similar but progressively more brightly shining and less strongly micro-reticulate. Epipleura: all narrow and very much longer than wide.

Ovipositor: extremely short, sheathed portion $0.2 \mathrm{I}$ as long as fore-wing; cylindro-compressed, dorsal valve weakly convex on tip.

MALE: differs from female as follows: Color: scape with a small white blotch near apex; tegula almost entirely white, except sometimes for a little brownish staining on apical margin; white blotches on hind-corners of propodeum sometimes even larger than in female, sometimes prolonged mesad and nearly contiguous

Fig. 1. Coccygomimus jakulicai, lateral view of mesosoma showing color pattern (male).

Fig. 2. Coccygomimus jakulicai, lateral view of hind leg (coxa to tibia), showing color pattern (male).

Fig. 3. Coccygomimus ramirezi, lateral view of hind leg (coxa to tibia), showing color pattern (male).

Fig. 4. Coccygomimus jakulicai, dorsal view of first gastric segment (female).

Fig. 5. Coccygomimus ramirezi, dorsal view of first gastric segment (female). 
apically; gaster with scarcely any white on the 8th tergite and practically without reddish staining even toward apex; fore-leg with coxa sometimes with a small dorso-lateral white blotch on apex in addition to the ventro-lateral white area and a little to much less redbrown staining than in female; trochanter white with a broad to very broad blackish stripe extending throughout above; trochantellus dull brown to orange with a more or less distinct white blotch below and often some whitish staining elsewhere; femur more orangebrown than in female and with the antero-dorsal white stripe broader and extending almost throughout; tibia dull white, above with a small premedian brown blotch and some more or less well developed orange brown or orangish tinging elsewhere and below broadly pallid orange brown on most of apical $2 / 3$; and tarsus with segments I-4 dull white with faint brown staining on apices and segment 5 dark brown; mid-leg with coxa even more broadly white than in female; trochanter with some black staining; femur with blackish staining on about apical I/9; tibia with a very broad white annulus that extends from about basal I/6 to apical I/3, more or less blackish brown basad of annulus and often more reddish brown behind; hind-leg with coxa sometimes with a faint whitish stain above near base; femur blackish stained on about apical I/6 to a little more than I/5; tibia black, practically without reddish staining, and with the premedian white annulus a little broader than in female; and tarsus more intensely black than in female, with a little brownish staining only near base of Ist segment.

Length of fore-wing: $6.2-6.6 \mathrm{~mm}$. Face: punctures slightly coarser and denser than in female, mostly adjacent to a little confluent. Clypeus: apex practically truncate. Temple: 0.62-0.80 as long as eye in lateral view. Malar space: $0.64-0.68$ as long as basal width of mandible.

Mesopleuron: with the punctures coarser and more generally reticulo-confluent than in female. Metapleuron: with definitely coarser sculpture than in female.

Propodeum: rather low and elongate; median longitudinal carinae sometimes more strongly suggested than in female; cristal angles even more pronouncedly subpyramidal than in female, the lateral longitudinal carinae sharp and high between cristae and hindrim of apical face; strong transverse wrinkling of basal face becoming reticulate and mingled with more or less distinct large punctures on basal $\mathrm{I} / 2$ of lateral field.

Ist gastric segment: postpetiole $0.70-0.78$ as long as wide at apex; sub-basal elevation of sternite a little blunter than in female; 
basal $3 / 4$ of postpetiole duller and more strongly sculptured than in female, with coarser micro-wrinkling which is irregularly transbiased on central field but more reticulate laterad, as well as with more numerous and more discrete intercalated punctures, particularly on lateral field. Succeeding tergites: 2 rather dully shining with strong, reticulate to trans-biased micro-wrinkling and abundant, moderately large, distinct but shallow to obscure, mostly adjacent to confluent punctures; 3 and 4 similar to 2 ; but 5-7 progressively more shining and with weaker punctures and wrinkling.

TyPES: The female holotype and one male paratype have been deposited in the collection of the Miguel Lillo Institute, San Miguel de Tucumán, Argentina. The second male paratype is in the collection of Charles C. Porter (RFD 3, Cambridge, Maryland, U.S.A.).

Discussion: The first record of $C$. jakulicai was a male collected near San Salvador de Jujuy during March of 1969, and in the author's revision of the South American Coccygomimus (Porter, I970, p. IIO) that specimen was associated tentatively with a Bolivian female therein described as $C$. ramirezi. However, subsequent discovery of a Salteñan female obviously conspecific with the male from Jujuy but different in several important features from the female of ramirezi confirmed that this Argentine form, although closely related to the Bolivian Coccygomimus, must be regarded as distinct.

Specifically, jakulicai may be distinguished from ramirezi by the following characters (see figures 2, 3, 4, and 5):

Tegula mostly white (instead of mostly blackish); gaster apically with extensive reddish staining; ground color of front femur reddish (instead of brownish black); ground color of fore-tibia pale red (instead of brownish black); hind-coxa red with a little dusky staining on apex (instead of red on basal $\mathrm{I} / 2$ and black on apical $\mathrm{I} / 2$ ) ; punctures of mesocutum medium sized and mostly well defined (instead of rather small and in large part very superficial and inconspicuous); mesopleuron and metapleuron more coarsely sculptured; propodeum less elongate, its basal face with rather strong and mostly regular transverse wrinkling (instead of with generally finer and extensively irregular wrinkling); postpetiole 0.65 (instead of 0.87 ) as long as wide at apex; first gastric tergite in profile with a rather high and rounded hump, its dorsal carinae faintly suggested on the hump and for a short distance rearward (instead of with a lower hump and with the dorsal carinae well defined on the hump and clearly traceable rearward about $2 / 3$ the length of postpetiole, 
on which they enclose a gently concave median area); and ovipositor 0.27 (instead of 0.15 ) as long as the fore-wing.

Another member of the Albomarginatus Group closely related both to jakulicai and ramirezi is the northwest Argentine $C$. tafiae Porter, but females of that species easily may be distinguished from the foregoing because they have the subalarum mostly white, the lower hind-corner of the mesopleuron marked with a large white blotch, the mesopleuron normally in great part without intercalated wrinkling among the punctures, the fore-tibia distinctly inflated, and the ovipositor 0.32 (instead of $0.15-0.21$ ) as long as the fore-wing. The male of jakulicai differs from that of tafiae in many of the same characters mentioned for the female and, moreover, may be separated by reference to couplet I I of the author's key to the males of South American Coccygomimus (Porter, 1970, p. 34) where it is treated under the name "ramirezi".

Habitat notes: The female holotype and one of the male paratypes were collected by a Malaise trap stationed in virgin Selva Tucumano-Boliviana at about $400 \mathrm{~m}$. elevation along the Río Pescado approximately $40 \mathrm{~km}$ west of Aguas Blancas in Salta Province. This is a very humid and almost tropical zone, without recorded frosts and with a short but definite dry season which becomes most pronounced between August and October. The second male paratype comes from Posta de Lozano, an area of mingled Selva and Chaco biota, located $18 \mathrm{~km}$ north of San Salvador de Jujuy at $\mathrm{I} 600$ m. elevation.

Specific name: For Dr. Domingo Jakúlica.

\section{AcKnowledgements}

Special thanks are due Dr. Domingo Jakúlica of the Universidad Nacional de Tucumán in Salta for his kindness in arranging numerous visits to the virgin subtropical forest near Aguas Blancas, where he owns extensive properties and maintains a camp that has served as base for our collecting.

It should be mentioned likewise, that this paper forms part of a series of studies of the Neotropic Ephialtinae initiated under Grant GB-6925 from the United States National Science Foundation.

The figures were inked by Srta. Alicia Sandoval.

Porter, C. C.

\section{REFERENCE}

1970. A Revision of the South American Species of Coccygomimus. Studia Ent. 13 : 1-192. 

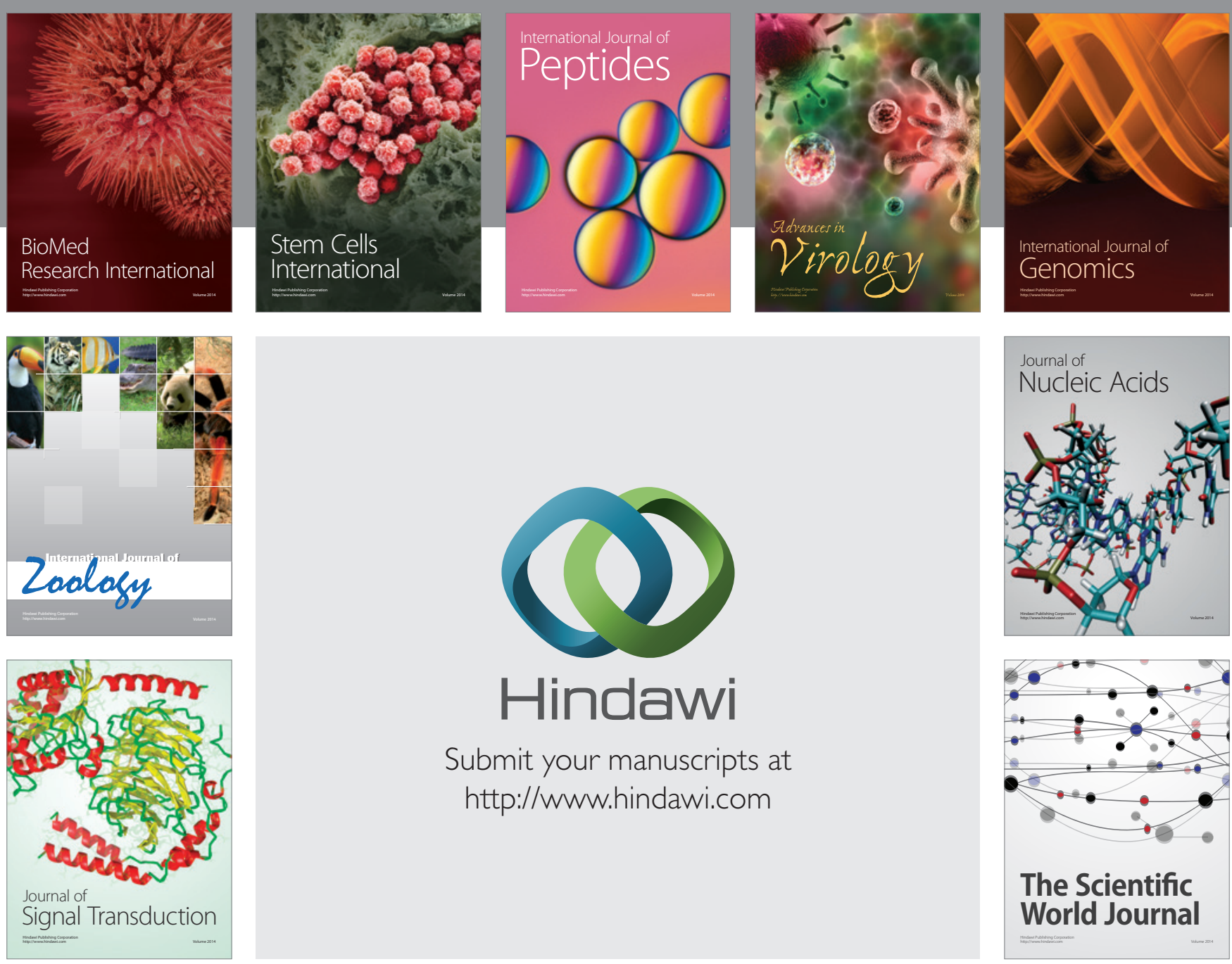

Submit your manuscripts at

http://www.hindawi.com
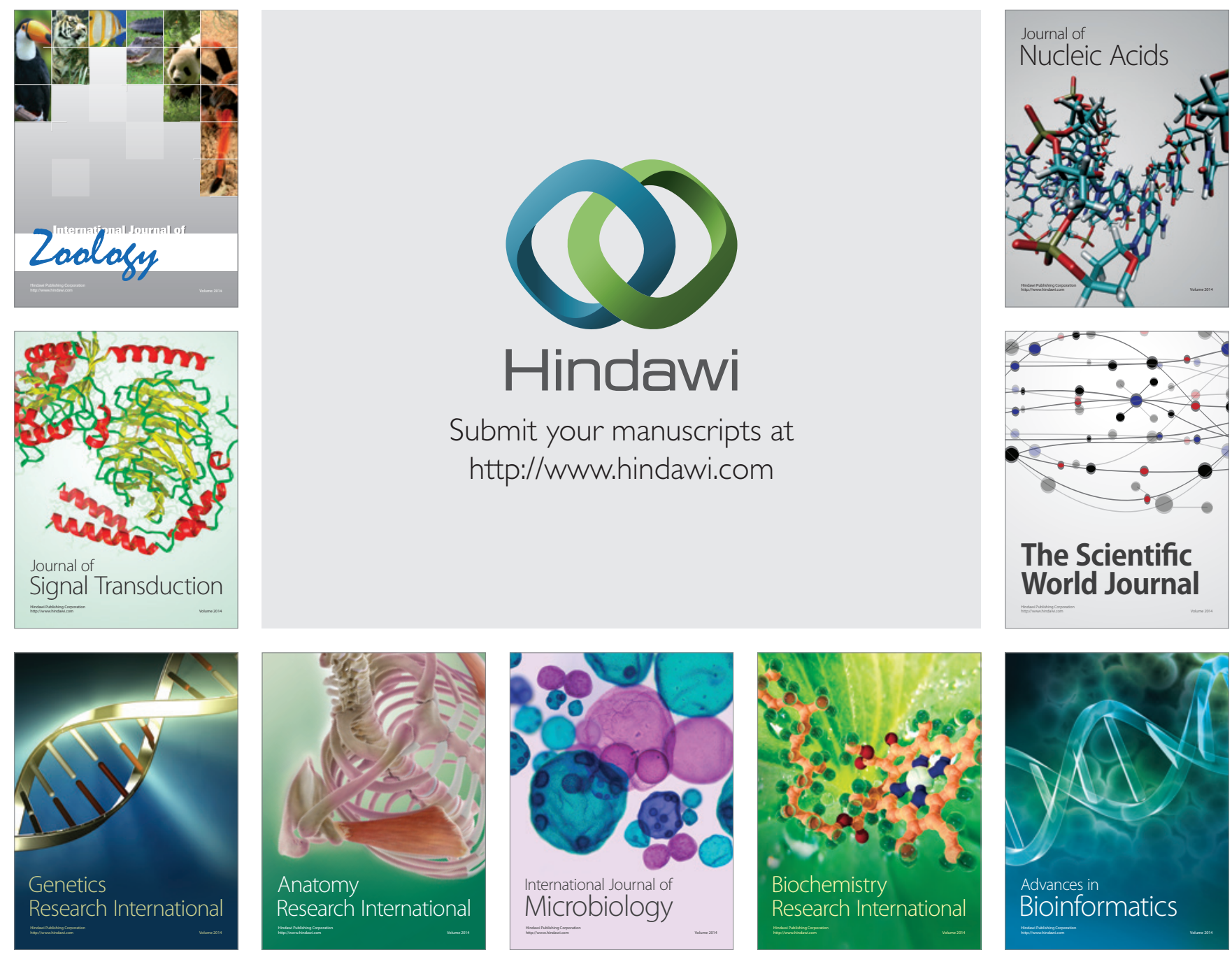

The Scientific World Journal
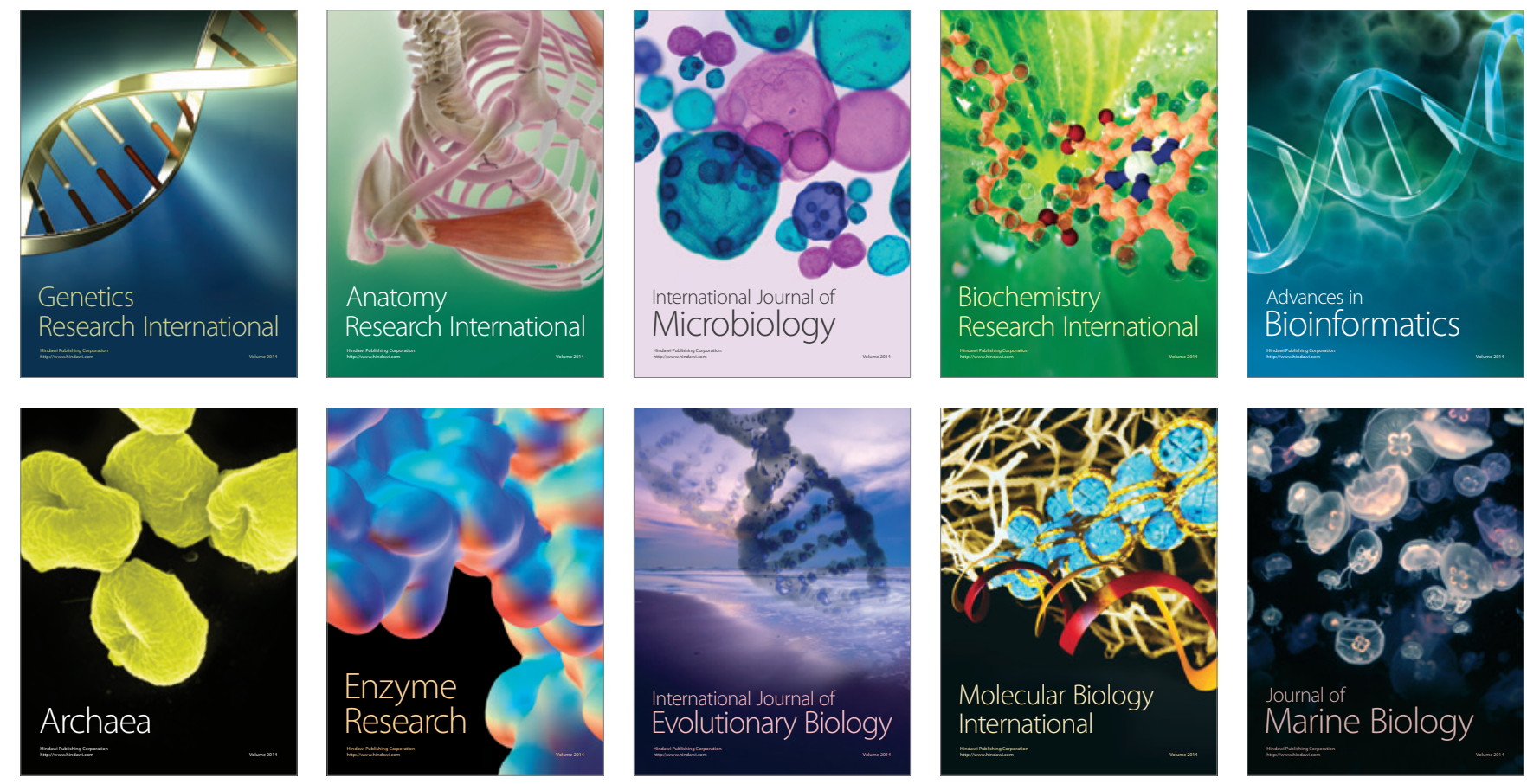